\title{
Effects of miRNA-15 and miRNA-16 expression replacement in Chronic Lymphocytic Leukemia: implication for therapy
}

Giovanna Cutrona ${ }^{1}$, Serena Matis ${ }^{1}$, Monica Colombo ${ }^{1}$, Carlotta Massucco ${ }^{1}$, Gabriella Baio ${ }^{2,3}$, Francesca Valdora $^{1,4}$, Laura Emionite ${ }^{5}$, Sonia Fabris ${ }^{6}$, Anna G. Recchia ${ }^{7,8}$, Massimo Gentile ${ }^{7,8}$, Carlo E. Neumaier ${ }^{2}$, Daniele Reverberi ${ }^{1}$, Rosanna Massara ${ }^{1}$, Simona Boccardo $^{9}$, Luca Basso ${ }^{10}$, Sandra Salvi $^{9}$, Francesca Rosa $^{10}$, Michele Cilli ${ }^{5}$, Simonetta Zupo ${ }^{11}$, Mauro Truini ${ }^{9,12}$, Pierfrancesco Tassone ${ }^{13}$, Massimo Calabrese ${ }^{2}$, Massimo Negrini ${ }^{14}$, Antonino Neri ${ }^{6,15}$, Fortunato Morabito $^{7,8}$, Franco Fais ${ }^{1,4}$, and Manlio Ferrarini ${ }^{16}$.

\section{Affiliations:}

${ }^{1}$ Molecular Pathology Unit, IRCCS-A.O.U. San Martino-IST, Genoa, Italy;

${ }^{2}$ Diagnostic Imaging and Senology, IRCCS-A.O.U. San Martino-IST, Genoa, Italy

${ }^{3}$ Current address: Aberdeen Biomedical Imaging Centre, University of Aberdeen, Aberdeen, UK. ${ }^{4}$ Department of Experimental Medicine, University of Genova, Genoa, Italy;

${ }^{5}$ Animal Facility, IRCCS-A.O.U. San Martino-IST, Genoa, Italy;

${ }^{6}$ Hematology Unit, Fondazione IRCCS Ca' Granda, Ospedale Maggiore Policlinico, Milan, Italy ${ }^{7}$ Hematology Unit, Department of Onco-Hematology, A.O. of Cosenza, Cosenza, Italy;

${ }^{8}$ Biotechnology Research Unit, Aprigliano, A.O./ASP of Cosenza, Cosenza, Italy;

${ }^{9}$ Division of Histopathology and Cytopathology, IRCCS-A.O.U. San Martino-IST, Genoa, Italy;

${ }^{10}$ Department of Science of Health (DISSAL), University of Genoa, Genoa, Italy;

${ }^{11}$ Molecular Diagnostic Unit, Division of Histopathology and Cytopathology, IRCCS-A.O.U. San Martino-IST, Genoa, Italy;

${ }^{12}$ Current address: A.O. Division of Histopathology and Cytogenetics, Ospedale Niguarda Ca'Granda, Milano, Italy;

${ }^{13}$ Department of Experimental and Clinical Medicine, Magna Graecia University, Salvatore Venuta University Campus, Catanzaro, Italy.

${ }^{14}$ Department of Morphology, Surgery and Experimental Medicine, University of Ferrara, Ferrara, Italy

${ }^{15}$ Department of Oncology and Hemato-Oncology, University of Milano, Milan, Italy;

${ }^{16}$ Scientific Direction, IRCCS-A.O.U. San Martino-IST, Genoa, Italy; 
32 Running title: Therapeutic approach with miR-15 and -16 in Chronic Lymphocytic Leukemia 33

34 Conflict of interest:

35 The authors declare no conflict of interest.

36

37 Correspondence:

38 Franco Fais, Dep. Integrated Oncological Therapies, Director of Molecular Pathology Unit, 39 IRCCS-AOU San Martino-IST, L.go Rosanna Benzi, 10; zip code 16132, Genoa, Italy. Phone: 40 +39-010-5558979; Fax: +39-010-5556531; E-mail: franco.fais@unige.it.

41 


\section{Abstract}

Chronic lymphocytic leukemia (CLL) clones are characterized by loss of a critical region in 13q14.3, [del(13)(q14)] involving the microRNA (miRNA) cluster miR-15a and miR-16-1. We have investigated the effects of replacement of miR-15a and miR-16-1. CLL cells transfected with these miRNA mimics exhibited a decrease in cell viability in vitro and impaired capacity for engraftment and growth in NOD/Shi-scid, $\gamma$ cnull (NSG) mice. No synergistic effects were observed when the two miRNA mimics were combined. The phenomena were not restricted to CLL with the del(13)(q14) lesion. Similar effects induced by miRNA mimics were seen in cells with additional chromosomal abnormalities with the exception of certain CLL clones harboring TP53 alterations. Administration of miRNA mimics to NSG mice previously engrafted with CLL clones resulted in substantial tumor regression. CLL cell transfection with miR-15a and miR-161 specific inhibitors resulted in increased cell viability in vitro and in an enhanced capacity of the engrafted cells to grow in NSG mice generating larger splenic nodules. These data demonstrate that the strong control by miR-15a and miR-16-1 on CLL clonal expansion is exerted also at the level of full-blown leukemia and provide indications for a miRNA based therapeutic strategy. 


\section{Introduction}

CLL is characterized by the monoclonal expansion of B cells expressing CD19, CD5 and CD23 and low levels of surface immunoglobulin ${ }^{1}$. The mechanisms underlying the disease have only been partially elucidated. In CLL, well-defined chromosomal abnormalities, such as deletions at $(17)(\mathrm{p} 13.1),(11)(\mathrm{q} 22.3)$ or trisomy $12(+12)$ are infrequent at early stages and more common in patients with more advanced disease or at relapse. Therefore, these lesions are unlikely to contribute to the initial pathogenetic mechanisms, although they may be involved in both disease progression and resistance to therapy ${ }^{2-8}$.

The $13 q 14.3[\operatorname{del}(13)(q 14)]$ deletion represents a remarkable exception, since it is observed in approximately $50 \%$ of cases either in a mono- or biallelic form and is also present in the early disease stages ${ }^{4,9}$, including monoclonal B cell lymphocytosis or $\mathrm{MBL}^{10,11}$, suggesting a pathogenetic role. The deletion identified involves primarily the DLEU2 gene which carries the locus of two microRNAs (miRNAs): miR-15a and miR-16-1 (miR-15 and miR-16, respectively $)^{12-17}$. MiRNAs are single stranded, non-coding RNA, which are evolutionary conserved and capable of regulating the expression of several genes concomitantly ${ }^{18}$. The regulation of gene expression occurs mainly through the specific binding of miRNAs to the 3'un-translated region (3'-UTR) of the messenger RNA of the target gene via a RNA-induced silencing complex ${ }^{19}$, although additional mechanisms have been described ${ }^{20}$.

Biallelic del(13)(q14) results in an incapacity of the cell to express miR-15 and miR-16 (ref. 14, 15, 17, 21, 22) (Supplementary Figure S1) and the deregulation of several target genes, including those involved in cell cycle progression and apoptosis ${ }^{23-25}$. This confers an increased resistance to apoptosis and a propensity to leukemic cell proliferation. Low levels of miR-15 or miR-16 are observed in patients with monoallelic deletions and in many patients without 
$81 \operatorname{del}(13)(q 14)$ (ref. 15, 21, 22, 26-28). Additional support for the role of the miR-15/miR-16 locus

82 in CLL pathogenesis comes from the New Zealand Black (NZB) mice strain harboring a germ-

83 line point mutation downstream of the miR-16 locus, which prevents normal expression of both

84 miR-15 and miR-16 and facilitates leukemia onset and possibly autoimmune manifestations ${ }^{29}$.

85 An analogous lesion, present in particular families, genetically predisposes humans to CLL and

86 possibly to other neoplasias ${ }^{30}$. Finally, the selective deletion of the miR-15/miR-16 locus in mice

87 predisposes the development of a CLL-like leukemia ${ }^{16,31}$. Therefore, impairment of miR-15 and

88 miR-16 function may be involved in promoting the initial phases of leukemogenesis; however,

89 little is known regarding the role of these lesions in maintaining the transformed status and the

90 clonal expansion of full-blown leukemia ${ }^{32}$.

91 Here, we investigated the possibility of interfering with both miR-15 and miR-16

92 expression by CLL cells, both in in vivo and in vitro. 


\section{Materials and Methods}

\section{Patients and CLL cell preparations.}

Newly diagnosed CLL patients from participating Institutions were enrolled within 12 months from diagnosis in the O-CLL1 protocol (clinicaltrial.gov identifier NCT00917540). All participants provided written informed consent in accordance with the declaration of Helsinki and the study was approved by the appropriate institutional review boards. Supplementary Table S1 summarizes the phenotype and the major cytogenetic features of CLL cases $(n=59)$ selected for in vitro $(\mathrm{n}=48)$ and in vivo $(\mathrm{n}=17)$ experiments reported in this study ${ }^{11,33,34}$.

PBMCs from patients with CLL were isolated by Ficoll-Hypaque (Seromed, Biochrom) density gradient centrifugation. In selected experiments, CD19-positive CLL cells were enriched by negative selection with the EasySep-Human B-cell Enrichment Kit without CD43 depletion (STEMCELL Technologies, Voden Medical Instruments S.p.A).

\section{Cell transfection}

MirVana $^{\mathrm{TM}}$ miRNA mimics or inhibitors (Ambion Inc, Thermo Fisher Scientific, Grand Island, NY, USA) were delivered to CLL cells with a Neon Transfection System (Invitrogen, Thermo Fisher Scientific) at the final concentration of $50 \mathrm{nM} / 2 \times 10^{6} \mathrm{CLL}$ cells. Optimal transfection and survival of CLL cells was obtained by applying 1 pulse at 2150 pulse voltage and 20 pulse width, as indicated by the manufacturer for the primary blood-derived suspension cells protocol. After transfection, cell suspensions were seeded in 24-well plates containing 500 $\mu \mathrm{L}$ of culture medium without antibiotics [RPMI-1640 with L-glutamine and 10\% FBS (Gibco, Thermo Fisher Scientific), Sodium piruvate $0.1 \%$ (Euroclone)] at $37^{\circ} \mathrm{C}$ and incubated at the final 
115 concentration of $2 \times 10^{6} \mathrm{CLL}$ cells $/ \mathrm{mL} /$ well in a $5 \% \mathrm{CO} 2$ atmosphere. The following miRNA 116 mimics and inhibitors were employed: hsa-miR-15a-5p, hsa-miR-16-5p, and miRNA Negative

117 Control (CTR)\#1, miRNA Inhibitor Negative CTR \#1.

\section{Evaluation of miRNA expression}

Detection Probes (Merck Millipore, France) in n=13 CLL cases and quantitative real time PCR (q-RT PCR) (n=38 CLL cases), Supplementary materials and methods and Figure S2).

SmartFlare technology is useful to study miRNA expression at the single-cell level. oligonucleotides duplexed with reporter strands (oligo+fluorophore). When Smartflare probes bind to their complementary RNA sequences the fluorophore is released and can be detected by flow-cytometry (FC). The following Smartflare probes conjugated with the Cyanine 5 (Cy5) fluorophore were used: SF-430/ miR-15a-5p (miR-15 CY5); SF-178/ miR-16-5p (miR-16 CY5); SF-102 /Scramble CTR Cy5. The latter reagent does not bind to any RNA sequences within the cells and is used to measure the level of background fluorescence within CLL cells. Cells were incubated with Smartflare probes overnight, harvested and analyzed by FACSCanto (BD Biosciences) and DIVA 6 (BD Biosciences) or FLOWJO V.9.8.3 software (Treestar Inc.). employed to evaluate cell viability. inhibitors were expressed as: 
$\%$ fold induction $=(\%$ smartflare positive cells transfected with $\mathrm{miR}-15 / \mathrm{miR}-16 \mathrm{mimic})$ -

138 (\%smartflare positive cells transfected with miR-CTR mimic) / (\%smartflare positive cells

139

140

141

142

143

144

145

146

147

148

149

150

151

152

153

154

155

156

157

158

159

transfected with miR-15/miR-16 mimic)*100

$\%$ fold inhibition $=(\%$ smartflare positive cells transfected with miR-CTR inhibitor $)-$ (\%smartflare positive cells transfected with miR-15/miR-16 inhibitor) / (\%smartflare positive cells transfected with miR-CTR inhibitor) $* 100$

\section{Apoptosis assays}

Cultured cells were double stained with Annexin V-FITC conjugate (cat. 556419, BD

Biosciences Pharmingen, San Josè, CA, USA), and PI in isotonic solution, and then analyzed by FC. Viable cells were defined as double negative cells ${ }^{35}$.

\section{Xenogeneic mouse transplantation}

Six to eight week old female NOD/Shi-scid, $\gamma$ cnull (NSG) mice (The Jackson Laboratory), a xenograft model for CLL growth in vivo ${ }^{36,37}$ were housed in sterile enclosures under specific pathogen-free conditions. All procedures involving animals were performed in the respect of the current National and International regulations and were reviewed and approved by the Licensing and Animal Welfare Body of the IRCCS-AOU San Martino-IST National Cancer Research Institute, Genoa, Italy.

Depending on the number of leukemic cells available for animal injection, groups of 2-3 NSG mice were employed for each test and treatment group. The number of animals used for each treatment is detailed in brackets in Table 1 and Supplementary Tables S3-S5. Full details are in Supplementary Material and Methods. 
In miRNA pre-treatment experiments NSG mice $(n=38)$ were inoculated with CLL cells

$161(\mathrm{n}=6)$ transfected with miRNA mimic/inhibitors and cultured for $6 \mathrm{~h}$ prior to injection. A total of

$16250 \times 10^{6}$ CLL cells per mouse were injected together with a proportion of autologous $\mathrm{T}$ cells

163 (approximately 5-10\%).

164

165

166

167

168

169

170

171

172

173

174

175

176

177

178

179

180

181

After four weeks, mice were anesthetized by intraperitoneal injection of combination of xylazine $(10 \mathrm{mg} / \mathrm{kg})$ and ketamine $(100 \mathrm{mg} / \mathrm{kg})$ and analyzed by Magnetic Resonance Imaging (MRI) with USPIO contrast reagent ${ }^{38}$.

On termination of the experiment (maximum 6 weeks from start), animals were sacrificed in a saturated $\mathrm{CO} 2$ chamber and autopsies were performed. Spleens were evaluated by FC and by immunohistochemical (IHC) analysis. The Animal Welfare Body posed a time limit to the experimental protocol to prevent unneeded suffering.

Fresh spleen samples were enzymatically digested using the Spleen Dissociation Kit (Miltenyi Biotec) and mechanically resuspended with gentleMACS ${ }^{\text {TM }}$ Dissociator (Miltenyi Biotec). The single-cell suspensions were stained with anti-human CD45-FITC (555482), CD19PECy7(557835), CD5-APC(555355), (BD Biosciences) and analyzed by FC. Apoptosis was evaluated using Annexin-V-FITC, CD19-PE-Cy7, CD5-PE (555353) (BD Biosciences), CD45APC(130-091-230, Miltenyi Biotec, ) cell staining.

Formalin-fixed and paraffin-embedded spleen specimens were analyzed for the presence of human CLL infiltrates and for the presence of co-injected bystander T-cells by IHC as detailed above ${ }^{38}$. The primary antibodies anti-CD20 Mouse monoclonal antibody (760-2531, clone L26- Ventana Medical System, Roche) and CD3 Rabbit Monoclonal Antibody (790-4341, clone 2GV6- Ventana Medical System, Roche) were incubated for $30 \mathrm{~min}$ at $37^{\circ} \mathrm{C}$ and signals 
revealed using the polymeric detection system, Ultraview Universal Red Detection Kit (Ventana Medical System). An appropriate positive tissue control was used for each staining run; the negative control consisted of performing the entire IHC procedure on adjacent sections in the absence of the primary antibody; the sections were counter-stained (automatically) with Gill's modified hematoxylin and then cover-slipped. The sections were evaluated by two observers with an Olympus light microscope using 4X, 10X, 40X and objectives under a Leica DMD108 optical digital microscope (Leica Microsystems).

To evaluate therapeutic effects of miRNA, CLL $(n=11)$ engraftment in the spleen was determined by MRI following USPIO contrast reagent injection after 2-3 weeks from cell injection. At this stage, mice were treated intraperitoneally [every second day with mirVana ${ }^{\mathrm{TM}}$ miRNA mimic, (In Vivo Ready formulation, Ambion Inc)] complexed with Invivofectamine 2.0 (Thermo Fisher Scientific) at a final concentration of $0.7 \mathrm{mg} / \mathrm{mL}(200 \mu \mathrm{L} / \mathrm{mouse})$. Overall three doses were administered. The following miRNA were used: hsa-miR-15a-5p, hsa-miR-16-5p, miRNA negative control\#1. Three days from the last injection, mice $(n=74)$ were analyzed again by MRI and then sacrificed in a saturated $\mathrm{CO} 2$ chamber and autopsies were performed. Spleens were analyzed by FC and IHC. Apoptosis was evaluated by Annexin-V-FITC, CD19-PE-Cy7, CD5-PE, CD45-APC, and FC or by Cleaved Caspase-3 (Asp175) (5A1E) Rabbit mAb (9664, Cell Signaling Technology, Danvers, MA, USA) and IHC on spleen tissue sections.

\section{Magnetic Resonance Imaging}

All in-vivo MRI experiments and MRI analyses, using USPIO nanoparticles, were carried out and acquired as previously described ${ }^{38}$. Details are reported in the Supplementary Information. 
The IHC index is a measure of the spread of leukemia based on the average diameters of

207 the follicular lesions. We assigned a numerical value of 1 to the follicles with diameters \pm s.d. of $208102( \pm 90) \times 42( \pm 7) \mu \mathrm{m}$; a value of 3 to follicles with a diameter $195( \pm 80) \times 138( \pm 85) \mu \mathrm{m}$; a value 209 of 6 to follicles between $399( \pm 245) \times 300( \pm 39)$, and a value of 12 to follicles between $734( \pm 461)$ $210 \times 540( \pm 167)$. The IHC index is given by the sum of the number of follicles multiplied by the 211 value assigned according to size (Supplementary Figure S3).

\section{Statistical analysis}

The statistical package SPSS for Windows, v13.0, 2004 software (SPSS UK) was used 215 for all analyses of statistical significance from adequately powered sample sizes for two-tailed 216 tests. Statistical comparisons between related samples were carried out by nonparametric 217 Wilcoxon signed rank (paired data) or by Mann-Whitney U (unpaired data) tests. A value of $218 \mathrm{P}<0.05$ was considered significant for all statistical calculations. Values are given as 219 mean \pm s.e.m. or mean \pm s.d. as stated in figure legends, which was calculated invariably from $n$ 220 (the number of patients or animals, biological replicates). All exact P-values are provided in the 221 figure panels, in figure legends or in Results section. 


\section{Results}

\section{Transfection of miR-15 and miR-16 mimics or inhibitors into CLL cells in vitro}

Transfection of miRNAs mimics or inhibitors into purified CLL cells was verified by FC using Smartflare technology and qRT-PCR.

For the experiments with miRNA mimics, 7 CLL cases with biallelic del(13)(q14) deletions were selected (Supplementary Information and Table S1 for case characteristics). At 24-h after transfection, a significantly larger number of cells were found to express miR-15 $(\%$ fold induction $=79 \pm 5$, mean \pm s.e.m. $)$ and miR-16 (\%fold induction=75 \pm 5$)$ compared to control preparations $(\mathrm{P}=0.015)$ (Figure 1a and Supplementary Figure S4a). Comparable data were obtained by qRT-PCR (Supplementary Figure S2a).

For experiments with miRNA inhibitors, we selected 6 CLL cases that did not display biallelic $\operatorname{del}(13)(\mathrm{q} 14)$ and expressed miR-15 and miR-16 to a variable extent. Transfection with specific miRNA inhibitors efficiently reduced miRNA expression in all CLL clones compared to controls $(\%$ fold inhibition $=54 \pm 4$, mean \pm s.e.m., for miR-15; and $\%$ fold inhibition $=59 \pm 4$ for miR16) $(\mathrm{P}=0.03)$ (Figure 1c and Supplementary Figure $\mathrm{S} 4 \mathrm{~b})$. Again, comparable data were obtained when miRNA expression was measured by qRT-PCR (Supplementary Figure S2b).

Since miR-15 and miR-16 expression may impact on CLL cell survival in vitro, purified cells from 12 CLL cases with biallelic del(13)(q14) were transfected with miR-15 or miR-16 miRNA mimics and cultured for up to $72 \mathrm{~h}$. Viable cells were measured at different time intervals (Supplementary Figure S5a shows the data of a representative experiment). A significant decrease in cell viability (\%fold reduction mean \pm s.e.m. $=53 \pm 7$ and $48 \pm 6$ for miR-15 and miR-16 mimics, respectively in 11/12 CLL samples) after $48 \mathrm{~h}$ ( $\mathrm{P}=0.001$ for miR-15 and 
$\mathrm{P}=0.0015$ for miR-16) was observed. Figure $1 \mathrm{~b}$ shows the pooled data from the tests performed while experiments on individual CLL cases are reported in Supplementary Figure S6a. Viability of cells from the CLL case CG0620, carrying a TP53 mutation, did not change, but the cells from two other CLL cases (MG0248, PA0254), also displaying TP53 mutations, showed a substantial drop in cell viability following transfection with either miR-15 or miR-16 (Supplementary Table S1 and Figure S6a).

Co-transfection of biallelic del(13)(q14) CLL cells with both miR-15 and miR-16 miRNAs never resulted in an additive/synergistic effect (data not shown). Consistent with previous observations, transfection of miR-15 or miR-16 into del(13)(q14) CLL cells caused down-regulation of BCL2 or MCL1 (antiapoptotic) and of Cyclin D1 or D2 (cell cycle induction) proteins encoded by target genes of these miRNAs ${ }^{23,24}$. In contrast, Survivin, which is involved in an alternative apoptotic pathway, was not down-regulated (Supplementary Figure S6b-c).

Inhibition of miR-15 or miR-16 expression with specific miRNA inhibitors resulted in a substantial increase in CLL cell viability. Supplementary Figure 5b reports the cell viability of a representative CLL case. A significant increase in cell viability was measured until 48-hours culture, whereas at 72 hours, a drop in cell viability was observed both in the presence of miR15/miR-16 inhibitors and in the presence of miR-CTR inhibitor, although there were still differences in the two conditions. Pooled viability data, measured after a 48-h culture from a group of 24 CLL cases displaying different cytogenetic features (Supplementary Table S2 and Supplementary Figure S7), are summarized in Figure 1d (\%fold increase $=40 \pm 3$ and $42 \pm 4$ with miR-15 or miR-16 inhibitor, respectively; $\mathrm{P}<0.0001$ ) and show that miRNA inhibition expression resulted consistently in a better in vitro survival of CLL cells. 


\section{Effects of in vitro transfection with miRNA-15 or miRNA-16 mimics/inhibitors on the growth}

\section{of CLL cells in NSG mice}

Purified cells from four CLL cases with biallelic del(13)(q14) were transfected with miR15, miR-16 or miR-CTR mimics, cultured for 6 -h and then injected intravenously (i.v.) into NSG mice together with autologous $\mathrm{T}$ cells (B/T cell ratio 5-10:1). Two/three mice were used for each treatment group. Disease engraftment was measured after 4 weeks by USPIO-MRI of the spleen $^{38}$. Iron uptake is inversely correlated with the presence of CLL follicles-like structures which prevent iron uptake. Signal-to-Noise ratio change $(\Delta \mathrm{SNR} \%)$ values are higher when low iron levels enter the splenic tissue. Thus, higher uptake of the USPIO contrast reagent was observed in the spleens of NSG mice receiving CLL cells transfected with miR-15 or miR-16 mimics which resulted into a lower $\Delta \mathrm{SNR} \%$ value compared to the spleens of mice receiving miR-CTR-transfected CLL cells (Figure 2a). The $\triangle \mathrm{SNR} \%$ of mice injected with miR-15 $($ mean \pm s.d. $=-31.1 \pm 25.1)$ or miR-16 (mean \pm s.d. $=-18.2 \pm 28.19)$ mimics pre-treated cells res.e.m.bled that of NSG mice that had not received leukemic cells (mean \pm s.d.. $=-54.3 \pm 15$ ), whereas this value was higher $(+30.7 \pm 23.4)$ in the mice receiving miR-CTR pre-treated cells. $\Delta \mathrm{SNR} \%$ values of mice groups pre-treated with miR-15 $(\mathrm{n}=7)$ or with miR-16 $(\mathrm{n}=6)$ were significantly lower compared to those pre-treated with miR-CTR $(n=8)(\mathrm{P}=0.001$ for miR-15; $\mathrm{P}=0.01$ for miR-16). This MRI pattern was likely related to the lower number of neoplastic foci within the splenic white pulp, a finding consistent with the observation of a lower number of follicle-like structures detected by IHC with anti-CD20 mAb in the spleen of mice receiving miR15/16 treated cells compared to controls. Likewise, the IHC index (as detailed in Supplementary Figure S3) of mice receiving CLL cells treated with miR-15/16 mimics was decreased compared to that of mice receiving cells transfected with miR-CTR. The average \pm s.d. 
of the IHC index reduction was $68 \pm 11$ and $67 \pm 11$ following transfection of miR-15 and miR-16 mimics, respectively (Figure $2 \mathrm{c})(\mathrm{P}=0.0078$ for both miRNAs compared to miR-CTR). FC showed a significantly lower proportion of CD19+CD5+ cells in the spleens of mice inoculated with miR-15/16-mimic-transfected CLL cells than in controls $(\mathrm{P}=0.012)$ (Figure 2e and supplementary Figure S8a). B cells recovered from NSG mice consistently shared the same BCR gene rearrangements as the leukemic clone used for injection, whereas $\mathrm{T}$ cells displayed oligoclonal TCR rearrangments (data not shown). miR-15 or miR-16 inhibitors in vitro and subsequently injected into NSG mice together with T cells according to the same schedule described above. This treatment resulted in a better splenic 300 engraftment of the CLL cells as documented by the differences in the $\Delta \mathrm{SNR} \%$ (Figure $2 \mathrm{~b}$ ). In the spleen of mice injected with the cells from PM608 CLL case, these values were of $+49 \pm 8.4$ and 302 $+33 \pm 19.3$ after pre-treatment of the cells with miR-15 and miR-16 inhibitors, respectively and of $+8 \pm 11.1$ after cell pretreatment with miR-CTR inhibitors. This was paralleled by an average IHC 304 index increase (mean \pm s.d..) of $69 \pm 6 \%$ and $71 \pm 17 \%$ respectively, in mice inoculated with miR-15 305 or miR-16 inhibitor pre-treated cells $(\mathrm{P}=0.039$ for miR-15 and $\mathrm{P}=0.05$ for miR-16 inhibitors compared to miR-CTR inhibitor, Figure 2d). Consistent with these data was the significant increase in the percentage of CD45+CD19+CD5+ cells observed by $\mathrm{FC}$ in the mice inoculated with miRNA-inhibitor-treated cells $(71 \pm 3 \%$ and $69 \pm 1 \%$, mean \pm s.d., respectively) (Figure $2 \mathrm{f}$, and supplementary Figure S8b). All data are detailed in Supplementary Table S3. Again, the BCR and TCR gene rearrangement analyses confirmed that the engrafted B cells were mostly from the 311 leukemic clones, whereas T cells were oligoclonal (not shown). 
Inhibition of CLL cell expansion in NSG mice by treatment with miR-15 and miR-16 mimics.

Next, we investigated whether administration of miRNA mimics could inhibit the expansion of a previously inoculated CLL clone in NSG mice. In preliminary tests, six NSG mice were injected with MG0248 CLL cells. After four weeks, a single potentially therapeutic dose of miR-15 miR-16 or miR-CTR complexed with Invivofectamine was administered intraperitoneally. Mice were sacrificed 24-h after miRNA administration and CLL cells (CD45+, CD19+ and CD5+) were purified by FACS sorting from splenic cell suspensions (the resulting preparations contained $>98 \%$ CLL cells). qRT-PCR analysis showed an increase of miR-15 (fold increase $=407.80$ ) and of miR-16 (fold increase 34.15) levels above control mice injected with miR-CTR (Supplementary Figure S9).

Next, CLL cells from six cases with biallelic del(13)(q14) were inoculated into NSG mice together with $\mathrm{T}$ cells (NSG-CLL) and CLL engraftment was verified in the spleen after approximately two weeks by $\mathrm{MRI}^{38}$. Mice found to have an above-average splenic $\Delta \mathrm{SNR} \%$, compared to NSG mice that had not received leukemic cells (NSG-CTR, $\mathrm{n}=12, \Delta \mathrm{SNR} \%$ $-54.3 \pm 15$, mean \pm s.d.), were placed on treatment with miR-15 or miR-16 mimics or miR-CTR (one injection on alternate days for a total of three injections). Three days after the final treatment, splenic infiltration by leukemic cells was evaluated (Figure 3 and 4). On MRI (exemplified in Figure $3 \mathrm{a}$ and $3 \mathrm{~b}$ ), miR-CTR treated mice displayed a splenic infiltration by leukemic cells with an $63 \pm 14$ average increase of $\Delta \mathrm{SNR} \%$ over that of mice not receiving leukemic cells $(\mathrm{p}<0.0001)$. In contrast, mice treated with miR-15 or miR-16 mimics showed a significant $\triangle \mathrm{SNR} \%$ decrease $(\mathrm{P}<0.0001$ and $\mathrm{P}=0.0002$, respectively) compared to mice before therapy administration (Figure 3c). The values of the treated mice were similar to those of NSGCTR mice not receiving CLL cell inocula. The $\triangle \mathrm{SNR} \%$ values of mice treated with miR-CTR 
336 following CLL cell inoculation were similar to or greater than those at therapy start time point

$337(\mathrm{P}=0.002)$ (Figure $3 \mathrm{c})$. These results predicted a response to therapy, which was subsequently 338 confirmed by FC analysis [average percentage CLL cells reduction of $61 \pm 8(\mathrm{P}=0.0006)$ and of $33975 \pm 12(\mathrm{P}=0.0001)$ after miR-15 and miR-16 mimics treatment, respectively versus mice treated 340 with miR-CTR] (Fig 3d) and IHC. A significantly lower IHC index was observed in mice treated 341 with miR-15 or miR-16 compared to mice treated with miR-CTR [(average IHC index reduction $34262 \pm 15(\mathrm{P}=0.0007)$ and $78 \pm 22(\mathrm{P}=0.02)$, respectively] (Figure 3e and Supplementary Table S4).

IHC analysis showed an almost complete disappearance of the typical aggregates of 344 leukemic $(\mathrm{CD} 20+)$ cells after treatment with miR-15 or miR-16 mimics (Figure 4a and 345 Supplementary Figure S3b). However, autologous T cells (CD3+ cells), surrounding what was 346 presumably the area of the previously existing CLL cell aggregates/nodules, were still present in 347 a substantial number, possibly indicating that $\mathrm{T}$ cells were not affected by treatment (Figure $4 \mathrm{~b}$ ). 348 Cleaved CASP3 could be observed in the "empty nodules" possibly indicating apoptotic 349 leukemic cells (Figure 4c and Supplementary Figure S10) as also suggested by the observation of 350 an increased percentage of Annexin V positive CLL cells $(\mathrm{P}<0.0001)$ in the splenic cell 351 suspension by FC (Figure 4d and Supplementary Table S5).

Decrease in vitro viability and growth ability of CLL cells with different cytogenetic features following transfection with miR-15 or miR-16 mimics

356 (Figure 5 and Supplementary Table S1). The cells from these cases, which expressed different levels of miR-15 and miR-16 as evaluated by qRT-PCR (Supplementary Figure S1c,d), were 358 purified and transfected with miR-15, miR-16 mimics or miR-CTR (Supplementary Figure S2c). 
Cell viability was significantly decreased following transfection in most cases $(\mathrm{P}<0.001$, Figure 5a, b). Decreased cell viability also was observed when the two major CLL groups were analyzed separately: i.e. those with monoallelic del(13)(q14) [statistically significant differences in the miR-15-mimic $(\mathrm{P}=0.01)$, miR-16-mimic $(\mathrm{P}=0.005)$ treated cells compared to controls] and the group with normal FISH $(\mathrm{P}=0.004)$.

In addition, viability of the cells from other cases, including one with del(11)(q22.3), involving the ATM gene, and others with p53 mutations or del(17)(p13.1) was reduced following miR-15 and miR-16 mimic transfection .

Finally, NSG mice were engrafted with cells from two cases harboring monoallelic del(13)(q14) (FP0499, GN0095), one case with trisomy 12 (RD0468), one with a normal FISH pattern (VS0624) and one with del(17)(p13.1) and a TP53 mutation on the remaining allele (RM0626), and were subsequently treated with miR-15 or miR-16 as above. A significant reduction of splenic disease was observed by $\mathrm{FC}(\mathrm{P}=0.0001$ and $\mathrm{P}=0.006$ following miR-15 or miR-16 mimic treatment, respectively compared to miR-CTR) (Table 1). A decrease in the IHC index of $72 \pm 18 \%$ and $74 \pm 10 \%$ following treatment with miR-15 and miR-16 mimics, respectively ( $\mathrm{P}=0.001)$ was observed in four of the CLL cases tested. Case RM0626 represented a remarkable exception since treatment with the miRNA mimics consistently failed to significantly block the growth of CLL cells in vivo. Of note is the finding that this case had low miR-15 and medium to high miR-16 expression. Thus, the findings were unlikely related to the possibility that the miRNA values were already so high that could not be changed by the transfection. Rather, a completely dysfunctional TP53 was the possible cause for the findings. 


\section{Discussion}

This study demonstrates that in vitro transfection of miR-15 and miR-16 mimics into CLL cells with del(13)(q14) results in a significant inhibition of their subsequent growth in NSG mice. Furthermore, administration of miR-15 or miR-16 mimics to NSG mice, in which these CLL cells were already engrafted and proliferating, caused significant tumor regression. Both observations are in line with the notion that miR-15 and miR-16 control the cell apoptotic apparatus and proliferative capacities ${ }^{17,23,24}$. No additive/synergistic effects were noted when miR-15 and miR-16 mimics were co-transfected, suggesting that the regulatory controls of the two miRNAs on the expression of other genes largely overlap, a consideration consistent with the notion that miR-15 and miR-16 interact with the same 3'-UTR region of BCL-2 mRNA ${ }^{24}$.

Selective inhibition of miR-15 and miR-16 expression in CLL cells resulted in improved in vitro survival and a more robust expansion in NSG mice ${ }^{16}$. In contrast, enforced expression of miR-15 or miR-16 in cells retaining the capacity to express these miRNAs resulted in impaired in vitro survival or diminished expansion in NSG mice. Both findings provide further support for the regulatory role of intracellular miR-15/miR-16 concentrations in full-blown CLL 14, 23, 24, 32 (Figure 5). The experimental design utilized here was intended to obtain a specific and selective inhibition or replacement of miR-15 and miR-16 without further influence of other gene segments such as Dleu2 or Dleu7 (ref. 39), the absence of which have been shown to synergize with that of miR-15 and miR-16 in CLL pathogenesis. Thus, the data demonstrate that low/absent expression of miR-15 and miR-16 plays a crucial pathogenetic role per sè, in line with the observation that replacement of these miRNAs in NZB mice using suitable viral carriers blocks the expansion of CLL-like cells both in vivo and in vitro ${ }^{40}$. 

are normally needed to support in vivo CLL cell growth. In the experiments where CLL cell growth in NSG mice was inhibited by pre-exposure to miR-15/miR-16 mimics in vitro (see 405 Figure 2), the T cells were added to the purified CLL cells following their in vitro exposure to

406

407 these miRNAs. However, in experiments, where transfection was carried out in vitro on unfractionated cell suspensions, containing both T and CLL cells, before injection into mice, we observed an unaltered distribution pattern of $\mathrm{T}$ cells in the spleen of mice even in the presence a largely diminished proportion of B cells. Moreover, when mice were treated with miR-15 or miR-16 mimics in vivo, seemingly unaltered $\mathrm{T}$ cell proportions were observed surrounding the “empty” areas, previously occupied by CLL cells (Figure 4). Thus, inhibition of CLL cell growth in NSG mice presumably occurred through interference of the transfected mimics with the CLL cell survival/proliferating apparatus, rather than through an indirect action on the $\mathrm{T}$ cells promoting CLL cell growth. Whether or not progressive CLL cell death, induced by the transfected miRNA mimics in vivo, may lead to $\mathrm{T}$ cell immune-priming capable of causing further CLL cell elimination is presently unknown.

A final issue concerns the potential use of miR-15 and miR-16 for therapy. MiRNA mimics are effective on CLL cells growing in vivo and on CLL cells with additional chromosomal alterations; however, some results from both in vivo and in vitro experiments showed that the presence of TP53 gene mutations/deletions may render administration of the miR-15 and miR-16 mimics ineffective. This is expected, given the close interactions between miR-15 and miR-16, TP53 and the cluster of miR-34 genes in the regulation of cell survival/apoptosis ${ }^{41,42}$. Nevertheless, not all cases with TP53 defects failed to respond to miRNA mimics treatment suggesting heterogeneity of functional TP53 alterations. These observations 
425 are being extended to additional cohorts of patients including more advanced stage/relapsed 426 patients that more frequently harbor additional TP53 alterations ${ }^{43-46}$.

We provide proof of principle data supporting the potential use of miRNA mimics to 428 block CLL clonal expansion. Additional miRNAs, other than miR-15 or miR-16, may become 429 suitable therapeutic targets, since a number of studies have demonstrated anomalous expression 430 of various miRNAs in CLL cells compared to normal cells ${ }^{11,22,30}$. Moreover, when certain 431 miRNA are overexpressed, they can be targeted by miRNA inhibitors ${ }^{47}$. Several anomalies in 432 miRNA expression have prognostic/predictive value for disease course and outcome, indicating a 433 potential mechanistic role in the disease pathogenesis/progression ${ }^{22-24,30,48-52}$. Thus, the miRNA 434 approach, especially if multiple miRNA mimics and inhibitors can be targeted, either alone or in 435 combination with other drugs, may represent an additional therapeutical strategy. In connection 436 with this, it should be noted that therapy with miR inhibition/replacement is being employed in a 437 variety of experimental tumors. Moreover, there are many available studies on human tumors, 438 some of which have reached the clinical stage I, with potentially promising results ${ }^{53}$. Thus, miR 439 therapy may represent a "real" tool in the future armamentarium of drugs usable in CLL, a 440 disease that so far has escaped attempts towards a radical cure. 
Acknowledgments: In addition to the Authors listed, the following investigators participated in this study as part of the GISL - Gruppo Italiano Studio Linfomi: Gianni Quintana, Divisione di Ematologia, Presidio Ospedaliero "A.Perrino", Brindisi; Giovanni Bertoldero, Dipartimento di Oncologia, Ospedale Civile, Noale, Venezia; Paolo Di Tonno, Dipartimento di Ematologia, Venere, Bari; Robin Foà and Francesca R Mauro, Divisione di Ematologia, Università La Sapienza, Roma; Nicola Di Renzo, Unità di Ematologia, Ospedale Vito Fazzi, Lecce; Maria Cristina Cox, Ematologia, A.O. Sant'Andrea, Università La Sapienza, Roma;Stefano Molica, Dipartimento di Oncologia ed Ematologia, Pugliese-Ciaccio Hospital, Catanzaro; Attilio Guarini, Unità di Ematologia e Trapianto di Cellule Staminali, Istituto di Oncologia "Giovanni Paolo II", Bari; Antonio Abbadessa, U.O.C. di Oncoematologia Ospedale "S. Anna e S. Sebastiano", Caserta; Francesco Iuliano, U.O.C. di Oncologia, Ospedale Giannettasio, Rossano Calabro, Cosenza; Omar Racchi, Ospedale Villa Scassi Sampierdarena, Genova; Mauro Spriano, Ematologia, A.O. San Martino, Genova; Felicetto Ferrara, Divisione di Ematologia, Ospedale Cardarelli, Napoli; Monica Crugnola, Ematologia, CTMO, Azienda Ospedaliera Universitaria di Parma; Alessandro Andriani, Dipartimento di Ematologia, Ospedale Nuovo Regina Margherita, Roma; Nicola Cascavilla, Unità di Ematologia e Trapianto di Cellule Staminali, IRCCS Ospedale Casa Sollievo della Sofferenza, San Giovanni Rotondo; Lucia Ciuffreda, Unità di Ematologia, Ospedale San Nicola Pellegrino, Trani; Graziella Pinotti, U.O. Oncologia Medica, Ospedale di Circolo Fondazione Macchi, Varese; Anna Pascarella, Unità Operativa di Ematologia, Ospedale dell'Angelo, Venezia-Mestre; Maria Grazia Lipari, Divisione di Ematologia, Ospedale Policlinico, Palermo, Francesco Merli, Unità Operativa di Ematologia, A.O.S. Maria Nuova, Reggio Emilia; Luca Baldini Istituto di Ricovero e Cura a Carattere Scientifico Cà Granda-Maggiore Policlinico, Milano; Caterina Musolino, Divisione di Ematologia, Università di Messina; Agostino Cortelezzi, Ematologia and CTMO, Foundation IRCCS Ca' Granda Ospedale Maggiore Policlinico, Milano; Francesco Angrilli, Dipartimento di Ematologia, Ospedale Santo Spirito, Pescara; Ugo Consoli, U.O.S. di Emato-Oncologia, Ospedale Garibaldi-Nesima, Catania; Gianluca Festini, Centro di Riferimento EmatologicoSeconda Medicina, Azienda Ospedaliero-Universitaria, Ospedali Riuniti, Trieste; Giuseppe Longo, Unità di Ematologia, Ospedale San Vincenzo, Taormina; Daniele Vallisa and Annalisa Arcari, Unità di Ematologia, Dipartimento di Onco-Ematologia, Guglielmo da Saliceto Hospital, Piacenza; Francesco Di Raimondo and Annalisa Chiarenza, Divisione di Ematologia, Università di Catania Ospedale Ferrarotto, Catania; Iolanda Vincelli, Unità di Ematologia, A.O. of Reggio Calabria; Donato Mannina, Divisione di Ematologia, Ospedale Papardo, Messina, Italy.

Funding: This work was supported by: Associazione Italiana Ricerca sul Cancro (AIRC) Grant 5 x mille n.9980, (to M.F., F.M. A. N., P.T. and M.N.) ; AIRC I.G. n. 14326 (to M.F.), n.10136 and 16722 (A.N.), n.15426 (to F.F.). AIRC and Fondazione CaRiCal co-financed Multi Unit Regional Grant 2014 n.16695 (to F.M.). Italian Ministry of Health 5x1000 funds (to S.Z. and F.F). A.G R. was supported by Associazione Italiana contro le Leucemie-Linfomi-Mielomi (AIL) Cosenza - Fondazione Amelia Scorza (FAS). S.M. C.M., M.C., L.E., S.B. were supported by AIRC.

Author contributions: Conception and design: G.C., G.B., F.F., M.F.; Development of methodology: G.C., S.M., C.M., G.B, M.C., D.R, R.M., S.S., S.B., L.E, S.F; Acquisition of data: G.C., S.M., L.E., M.C., G.B., M.M., S.F., S.S., D.R, R.M., F.V., S.Z., F.M., M.N.; Analysis and interpretation of data : G.C., S.M., G.B., C.M, A.N., S.S., M.C., S.F, C.E.N, M.C., F.R, L.B, 
F.F., S.Z., M.N., P.T., M.G., M.T., M.F., F.M.; Writing, review, and/or revision of the manuscript: G.C, A.G.R., M.N., P.T., A.N., F.F., M.F.; Study supervision: G.C., F.F, M.F. All authors reviewed and approved the manuscript.

Supplementary information is available at Leukemia website (http://www.nature.com/leu)

\section{References}

1. Chiorazzi N, Rai KR, Ferrarini M. Chronic lymphocytic leukemia. N Engl J Med 2005; 352(8): 804-815.

2. Dohner H, Stilgenbauer S, James MR, Benner A, Weilguni T, Bentz M, et al. 11q deletions identify a new subset of B-cell chronic lymphocytic leukemia characterized by extensive nodal involvement and inferior prognosis. Blood 1997; 89(7): 2516-2522.

3. Neilson JR, Auer R, White D, Bienz N, Waters JJ, Whittaker JA, et al. Deletions at 11q identify a subset of patients with typical CLL who show consistent disease progression and reduced survival. Leukemia 1997; 11(11): 1929-1932.

4. Dohner H, Stilgenbauer S, Benner A, Leupolt E, Krober A, Bullinger L, et al. Genomic aberrations and survival in chronic lymphocytic leukemia. N Engl J Med 2000; 343(26): 1910-1916.

5. Grever MR, Lucas DM, Dewald GW, Neuberg DS, Reed JC, Kitada S, et al. Comprehensive assessment of genetic and molecular features predicting outcome in 
patients with chronic lymphocytic leukemia: results from the US Intergroup Phase III Trial E2997. J Clin Oncol 2007; 25(7): 799-804.

6. Stilgenbauer S, Zenz T, Winkler D, Buhler A, Schlenk RF, Groner S, et al. Subcutaneous alemtuzumab in fludarabine-refractory chronic lymphocytic leukemia: clinical results and prognostic marker analyses from the CLL2H study of the German Chronic Lymphocytic Leukemia Study Group. J Clin Oncol 2009; 27(24): 3994-4001.

7. Fischer K, Cramer P, Busch R, Bottcher S, Bahlo J, Schubert J, et al. Bendamustine in combination with rituximab for previously untreated patients with chronic lymphocytic leukemia: a multicenter phase II trial of the German Chronic Lymphocytic Leukemia Study Group. J Clin Oncol 2012; 30(26): 3209-3216.

8. Zenz T, Habe S, Denzel T, Mohr J, Winkler D, Buhler A, et al. Detailed analysis of p53 pathway defects in fludarabine-refractory chronic lymphocytic leukemia (CLL): dissecting the contribution of $17 \mathrm{p}$ deletion, TP53 mutation, p53-p21 dysfunction, and miR34a in a prospective clinical trial. Blood 2009; 114(13): 2589-2597.

9. Kalachikov S, Migliazza A, Cayanis E, Fracchiolla NS, Bonaldo MF, Lawton L, et al. Cloning and gene mapping of the chromosome 13q14 region deleted in chronic lymphocytic leukemia. Genomics 1997; 42(3): 369-377. 
533 10. Rawstron AC, Bennett FL, O'Connor SJ, Kwok M, Fenton JA, Plummer M, et al.

534

535

536

537

538

539

540

541

542

543

544

545

546

547

548

549

550

551

552 553 Monoclonal B-cell lymphocytosis and chronic lymphocytic leukemia. N Engl J Med 2008; 359(6): 575-583.

11. Morabito F, Mosca L, Cutrona G, Agnelli L, Tuana G, Ferracin M, et al. Clinical monoclonal B lymphocytosis versus Rai 0 chronic lymphocytic leukemia: A comparison of cellular, cytogenetic, molecular, and clinical features. Clin Cancer Res 2013; 19(21): $5890-5900$.

12. Liu Y, Corcoran M, Rasool O, Ivanova G, Ibbotson R, Grander D, et al. Cloning of two candidate tumor suppressor genes within a $10 \mathrm{~kb}$ region on chromosome $13 \mathrm{q} 14$, frequently deleted in chronic lymphocytic leukemia. Oncogene 1997; 15(20): 2463-2473.

13. Migliazza A, Bosch F, Komatsu H, Cayanis E, Martinotti S, Toniato E, et al. Nucleotide sequence, transcription map, and mutation analysis of the $13 \mathrm{q} 14$ chromosomal region deleted in B-cell chronic lymphocytic leukemia. Blood 2001; 97(7): 2098-2104.

14. Calin GA, Dumitru CD, Shimizu M, Bichi R, Zupo S, Noch E, et al. Frequent deletions and down-regulation of micro- RNA genes miR15 and miR16 at 13q14 in chronic lymphocytic leukemia. Proc Natl Acad Sci U S A 2002; 99(24): 15524-15529. 
554 15. Mosca L, Fabris S, Lionetti M, Todoerti K, Agnelli L, Morabito F, et al. Integrative genomics analyses reveal molecularly distinct subgroups of B-cell chronic lymphocytic leukemia patients with 13q14 deletion. Clin Cancer Res 2010; 16(23): 5641-5653.

16. Klein U, Lia M, Crespo M, Siegel R, Shen Q, Mo T, et al. The DLEU2/miR-15a/16-1

17. Sellmann L, Scholtysik R, Kreuz M, Cyrull S, Tiacci E, Stanelle J, et al. Gene dosage effects in chronic lymphocytic leukemia. Cancer Genet Cytogenet 2010; 203(2): 149-

18. Lagos-Quintana M, Rauhut R, Lendeckel W, Tuschl T. Identification of novel genes coding for small expressed RNAs. Science 2001; 294(5543): 853-858.

19. Ghildiyal M, Zamore PD. Small silencing RNAs: an expanding universe. Nat Rev Genet 571 2009; 10(2): 94-108. 
575 21. Ouillette P, Erba H, Kujawski L, Kaminski M, Shedden K, Malek SN. Integrated

576

577

578

579

580

581

582

583

584

585

586

587

588

589

590

591

592

593

594

595 genomic profiling of chronic lymphocytic leukemia identifies subtypes of deletion 13q14. Cancer Res 2008; 68(4): 1012-1021.

22. Negrini M, Cutrona G, Bassi C, Fabris S, Zagatti B, Colombo M, et al. microRNAome expression in chronic lymphocytic leukemia: comparison with normal B-cell subsets and correlations with prognostic and clinical parameters. Clin Cancer Res 2014; 20(15): 4141-4153.

23. Calin GA, Cimmino A, Fabbri M, Ferracin M, Wojcik SE, Shimizu M, et al. MiR-15a and miR-16-1 cluster functions in human leukemia. Proc Natl Acad Sci U S A 2008; 105(13): 5166-5171.

24. Cimmino A, Calin GA, Fabbri M, Iorio MV, Ferracin M, Shimizu M, et al. miR-15 and miR-16 induce apoptosis by targeting BCL2. Proc Natl Acad Sci U S A 2005; 102(39): 13944-13949.

25. Linsley PS, Schelter J, Burchard J, Kibukawa M, Martin MM, Bartz SR, et al. Transcripts targeted by the microRNA-16 family cooperatively regulate cell cycle progression. Mol Cell Biol 2007; 27(6): 2240-2252. 
596 26. Allegra D, Bilan V, Garding A, Dohner H, Stilgenbauer S, Kuchenbauer F, et al.

597 Defective DROSHA processing contributes to downregulation of MiR-15/-16 in chronic $598 \quad$ lymphocytic leukemia. Leukemia 2014; 28(1): 98-107.

599

600 27. Veronese A, Pepe F, Chiacchia J, Pagotto S, Lanuti P, Veschi S, et al. Allele-specific loss 601

602 and transcription of the miR-15a/16-1 cluster in chronic lymphocytic leukemia. Leukemia $2015 ; 29(1): 86-95$.

603

604

28. Mertens D, Wolf S, Tschuch C, Mund C, Kienle D, Ohl S, et al. Allelic silencing at the 605 606 tumor-suppressor locus 13q14.3 suggests an epigenetic tumor-suppressor mechanism. Proc Natl Acad Sci U S A 2006; 103(20): 7741-7746.

607

608

609

610

611

612 30. Calin GA, Ferracin M, Cimmino A, Di Leva G, Shimizu M, Wojcik SE, et al. A

614

29. Raveche ES, Salerno E, Scaglione BJ, Manohar V, Abbasi F, Lin YC, et al. Abnormal microRNA-16 locus with synteny to human 13q14 linked to CLL in NZB mice. Blood 2007; 109(12): 5079-5086.

615

616 31. Underbayev C, Kasar S, Ruezinsky W, Degheidy H, Schneider JS, Marti G, et al. Role of 617 618 MicroRNA signature associated with prognosis and progression in chronic lymphocytic leukemia. N Engl J Med 2005; 353(17): 1793-1801. mir-15a/16-1 in early B cell development in a mouse model of chronic lymphocytic leukemia. Oncotarget 2016. 
32. Pekarsky Y, Croce CM. Role of miR-15/16 in CLL. Cell Death Differ 2015; 22(1): 6-11.

621

622

623

624

625

626

627

628

629

630

631

632

633

634

635

636

637

638

639

640

33. Morabito F, Cutrona G, Gentile M, Fabris S, Matis S, Vigna E, et al. Is ZAP70 still a key prognostic factor in early stage chronic lymphocytic leukaemia? Results of the analysis from a prospective multicentre observational study. Br J Haematol 2015; 168(3): 455459.

34. Lionetti M, Fabris S, Cutrona G, Agnelli L, Ciardullo C, Matis S, et al. High-throughput sequencing for the identification of NOTCH1 mutations in early stage chronic lymphocytic leukaemia: biological and clinical implications. Br J Haematol 2014; 165(5): 629-639.

35. Cutrona G, Colombo M, Matis S, Fabbi M, Spriano M, Callea V, et al. Clonal heterogeneity in chronic lymphocytic leukemia cells: superior response to surface IgM cross-linking in CD38, ZAP-70-positive cells. Haematologica 2008; 93(3): 413-422.

36. Durig J, Ebeling P, Grabellus F, Sorg UR, Mollmann M, Schutt P, et al. A novel nonobese diabetic/severe combined immunodeficient xenograft model for chronic lymphocytic leukemia reflects important clinical characteristics of the disease. Cancer Res 2007; 67(18): 8653-8661. 
641 37. Bagnara D, Kaufman MS, Calissano C, Marsilio S, Patten PE, Simone R, et al. A novel 642 adoptive transfer model of chronic lymphocytic leukemia suggests a key role for $\mathrm{T}$ $643 \quad$ lymphocytes in the disease. Blood 2011; 117(20): 5463-5472.

644

645 38. Valdora F, Cutrona G, Matis S, Morabito F, Massucco C, Emionite L, et al. A non646

39. Palamarchuk A, Efanov A, Nazaryan N, Santanam U, Alder H, Rassenti L, et al. 13q14 invasive approach to monitor chronic lymphocytic leukemia engraftment in a xenograft mouse model using ultra-small superparamagnetic iron oxide-magnetic resonance imaging (USPIO-MRI). Clin Immunol 2016.

653 deletions in CLL involve cooperating tumor suppressors. Blood 2010; 115(19): 39163922.

40. Kasar S, Salerno E, Yuan Y, Underbayev C, Vollenweider D, Laurindo MF, et al. Systemic in vivo lentiviral delivery of miR-15a/16 reduces malignancy in the NZB de novo mouse model of chronic lymphocytic leukemia. Genes Immun 2012; 13(2): 109119.

41. Fabbri M, Bottoni A, Shimizu M, Spizzo R, Nicoloso MS, Rossi S, et al. Association of a microRNA/TP53 feedback circuitry with pathogenesis and outcome of B-cell chronic lymphocytic leukemia. JAMA 2011; 305(1): 59-67.

662 
663

664

665

666

667

668

669

670

671

672

673

674

675

676

677

678

679

680

681

682

683

42. Lin K, Farahani M, Yang Y, Johnson GG, Oates M, Atherton M, et al. Loss of MIR15A and MIR16-1 at 13q14 is associated with increased TP53 mRNA, de-repression of BCL2 and adverse outcome in chronic lymphocytic leukaemia. Br J Haematol 2014; 167(3): 346-355.

43. Herling CD, Klaumunzer M, Rocha CK, Altmuller J, Thiele H, Bahlo J, et al. Complex karyotypes and KRAS and POT1 mutations impact outcome in CLL after chlorambucilbased chemotherapy or chemoimmunotherapy. Blood 2016; 128(3): 395-404.

44. Rossi D, Rasi S, Spina V, Bruscaggin A, Monti S, Ciardullo C, et al. Integrated mutational and cytogenetic analysis identifies new prognostic subgroups in chronic lymphocytic leukemia. Blood 2013; 121(8): 1403-1412.

45. Landau DA, Carter SL, Stojanov P, McKenna A, Stevenson K, Lawrence MS, et al. Evolution and impact of subclonal mutations in chronic lymphocytic leukemia. Cell 2013; 152(4): 714-726.

46. Guieze R, Robbe P, Clifford R, de Guibert S, Pereira B, Timbs A, et al. Presence of multiple recurrent mutations confers poor trial outcome of relapsed/refractory CLL. Blood 2015; 126(18): 2110-2117. 
47. Saleh LM, Wang W, Herman SE, Saba NS, Anastas V, Barber E, et al. Ibrutinib downregulates a subset of miRNA leading to upregulation of tumor suppressors and inhibition of cell proliferation in chronic lymphocytic leukemia. Leukemia 2016.

48. Calin GA, Liu CG, Sevignani C, Ferracin M, Felli N, Dumitru CD, et al. MicroRNA profiling reveals distinct signatures in B cell chronic lymphocytic leukemias. Proc Natl Acad Sci U S A 2004; 101(32): 11755-11760.

49. Visone R, Rassenti LZ, Veronese A, Taccioli C, Costinean S, Aguda BD, et al. Karyotype-specific microRNA signature in chronic lymphocytic leukemia. Blood 2009; 114(18): 3872-3879.

50. Pekarsky Y, Santanam U, Cimmino A, Palamarchuk A, Efanov A, Maximov V, et al. Tcl1 expression in chronic lymphocytic leukemia is regulated by miR-29 and miR-181. Cancer Res 2006; 66(24): 11590-11593.

51. Bresin A, Callegari E, D'Abundo L, Cattani C, Bassi C, Zagatti B, et al. miR-181b as a therapeutic agent for chronic lymphocytic leukemia in the Emicro-TCL1 mouse model. Oncotarget 2015; 6(23): 19807-19818.

52. Visone R, Veronese A, Rassenti LZ, Balatti V, Pearl DK, Acunzo M, et al. miR-181b is a biomarker of disease progression in chronic lymphocytic leukemia. Blood 2011; 118(11): 3072-3079. 
707 53. Shah MY, Ferrajoli A, Sood AK, Lopez-Berestein G, Calin GA. microRNA Therapeutics in Cancer - An Emerging Concept. EBioMedicine 2016; 12: 34-42. 


\section{Figure legends}

710

711

712

713

714

715

716

717

718

719

720

721

722

723

724

725

726

727

728

729

730

731

Figure 1. Transfection with miRNA mimics and inhibitors and variations in CLL cell viability in vitro. (a) Expression of miR-15 and miR-16 following transfection with miR-15 (\% of positive CLL cells mean \pm s.e.m. $=55.7 \pm 5.2)$ or miR-16 $(49.1 \pm 7.6)$ or miR-CTR mimics (10.9 \pm 2.2 for miR-15; $10.8 \pm 1.9$ for miR-16) determined by smartflare technology. Summary of tests on 7 CLL cases with biallelic del(13)(q14) (MG0248, DT0300, MA0088, LD0062, GM0041, RD0296, GD0051).(b) Summary of viability determinations obtained on cells from 12 different biallelic del(13)(q14) CLL cases after a 48-h culture following transfection of the indicated miRNA-mimics (data for individual cases are reported in Supplementary Figure S6a). The asterisks indicate data from a CLL case (CG0620) harboring the TP53 mutation (Supplementary Table S1). (c) Expression of miR-15 and miR-16 following transfection with

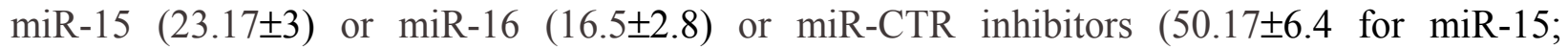

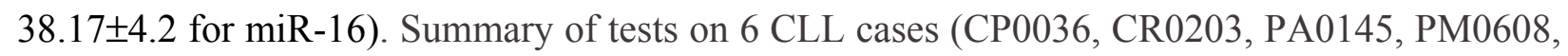
CG0623, MA0342). (d) Summary of the viability results obtained on cells from 24 CLL cases transfected with miRNA inhibitors. In (a) and (c) purified CLL cells were transfected with the indicated miRNA mimics or inhibitors and cultured overnight in the presence of miR-15-CY5, miR-16-CY5 or scramble CY5 Smartflare probes. Counter staining with propidium iodide (PI) was employed to evaluate cell viability (see also Supplementary Figure S4). In (b) and (d) viable cells (\%) are measured as Annexin-V/PI-double negative cells (Supplementary Figure S5). The $P$-values were obtained by Wilcoxon test in all panels.

\section{Figure 2. CLL cell engraftment in NSG mice following in vitro transfection with miRNA}

mimics or inhibitors. Representative tests on mice engrafted with CLL cells pre-treated in vitro 
with miRNA mimics (CLL CD0310), miRNA inhibitors (CLL PM0608), or miRNA-CTR. (a-b) The figure shows the MRI images $24 \mathrm{~h}$ after USPIO administration. The position of the spleen is indicated by the dotted red outline. $\triangle \mathrm{SNR} \%$ values also are indicated. The spleens with superior iron uptake and consequent lower $\Delta \mathrm{SNR} \%$ values, appear darker and less nodular. Conversely, spleens with lower iron uptake and higher $\Delta \mathrm{SNR} \%$ values are not so dark and show a nodular structure possibly related to the presence of follicles. Additional explanations are given in text. (c-d) $\alpha$-CD20 Ab staining (red) of paraffin tissue embedded spleen samples following injection of CLL cells pre-treated with the indicated miRNA (d). The CD20+ follicle-like structures are highlighted by red squares in (c) (magnification 40x). The 400x magnification of a representative follicle for each panel is shown. IHC index is indicated in each panel. (e-f) Flow-cytometry analysis of cells from of the same spleens used for the IHC analyses shown in (c) and (d). CLL cells (CD5+/CD19+) and T cells (CD5+/CD19-) were identified on gated huCD45-positive cells (Supplementary Figure S8). (e) Pooled flow-cytometry data obtained from 4 CLL cases with biallelic del(13)(q14) pre-treated with miRNA mimics in vitro before injection into mice $(\mathrm{n}=8$ mice for each treatment group). The cells, harvested from mice at the end of tests, were stained and counted. Statistical comparisons were carried out using Wilcoxon-matched pair test. A Pvalue $=0.0078$ is indicated by $* *$. (f) Pooled flow-cytometry data on cells from 2 CLL cases with normal FISH pre-treated in vitro with miRNA inhibitors prior to injection into mice ( $\mathrm{n}=5$ mice for miR-CTR, $\mathrm{n}=4$ for miR-15 and $\mathrm{n}=5$ for miR-16 inhibitors). ${ }^{*}$ and $* *$ indicate $\mathrm{P}=0.016$ and $\mathrm{P}=0.007 \mathrm{P}$-values respectively (Mann-Whitney $\mathrm{U}$ test). In (e-f) values are expressed as mean \pm s.d. and detailed in Supplementary Table S3. 


\section{Figure 3. Effects of in vivo treatment with miRNA mimics on CLL cells engrafted in NSG}

mice. (a-b) MRI analysis of the spleen before and after the indicated treatment (representative experiment with cells from MP0456 CLL case). (MRI) images obtained $24 \mathrm{~h}$ after Spleens which are characterized by high USPIO uptake appear darker and less granular, a finding which correlates with a low presence of leukemic follicles. See text and legend to Fig. 2 for additional details. (c) Summary of MRI results observed on cells from 6 CLL cases biallelic for $\operatorname{del}(13)(q 14)$ treated with the indicated miRNA mimics. After 2 weeks from CLL cells injection (NSG-CLL, grey dots), mice displayed $\triangle \mathrm{SNR} \%$ values significantly higher compared to those not receiving CLL cells (NSG-CTR, green dots). NSG-CLL mice treated with miR-15 (red dots) or miR-16 (blue dots) mimics had significantly different MRI patterns from the same mice before therapy or after treatment with miR-CTR (black dots). (d) Summary of the flowcytometry analysis of freshly isolated cells from the same spleens analyzed in (c). Percentages of CD19+CD5+ CLLs cells or CD19-CD5+ T cells detected by gating CD45+ cells are expressed as mean \pm s.d.. (e) Summary of the IHC analysis of splenic tissue stained by $\alpha-C D 20$ mAb. In (c,

d, e) each dot represents an individual mouse. Values also are expressed as mean \pm s.d.. Statistical comparisons were carried out using Mann-Whitney $U$ test. All data are detailed in Supplementary Table S4.

Figure 4. Effects of treatment with miR-15 or miR-16 mimics on the expansion of CLL clones in NSG mice. (a-b) IHC analysis of the spleen of a mouse a representative CLL case (MP0456).The typical CD20+ aggregates (a) surrounded by CD3 + T cells (b), that are evident in the spleens of the mice treated with miR-CTR, virtually disappear following treatment with miR15 or miR-16 mimics. 40x magnification view of splenic sagittal sections. The inset indicates the same areas at a higher magnification (400x). (c) Numerous cells were stained by $\alpha$-Cleaved 
778 Caspase $3 \mathrm{mAb}$ in the spleen of mice treated with miR-15. These were virtually absent in mice 779 treated with miR-CTR (magnification 200x and 400x in the inset). (d) Summary of flow780 cytometry results observed in mice injected with the cells from 6 CLL cases biallelic for 781 del(13)(q14.3). Annexin-V positive cells were determined at the end of the experiment. Each dot 782 represents an individual mouse. Values are expressed as mean \pm s.d.. Statistical comparisons were 783 carried out using Mann-Whitney $\mathrm{U}$ test $(* * * * \mathrm{P}<0.0001)$. All data are detailed in Supplementary 784 Table S5.

Figure 5. Effects of treatment with miRNA mimics on the growth of cells from CLL with non-biallelic del(13)(q14. (a) Determination of viable cells (measured as Annexin V/PInegative cells) in 26 CLL cases at 48 -h culture following transfection of the indicated miRNA mimics. CLL cases were grouped according to their karyotype. The asterisks indicate CLL cases carrying TP53 alterations (Supplementary Table S1). (b) Summary of the results of the 26 CLLs cases (left panel) and subdivided in cases with monoallelic del(13)(q14) (n=12) (central panel)

792 and with normal FISH (n=9) (right panel). P-values shown were calculated by Wilcoxon test. 
793 
a

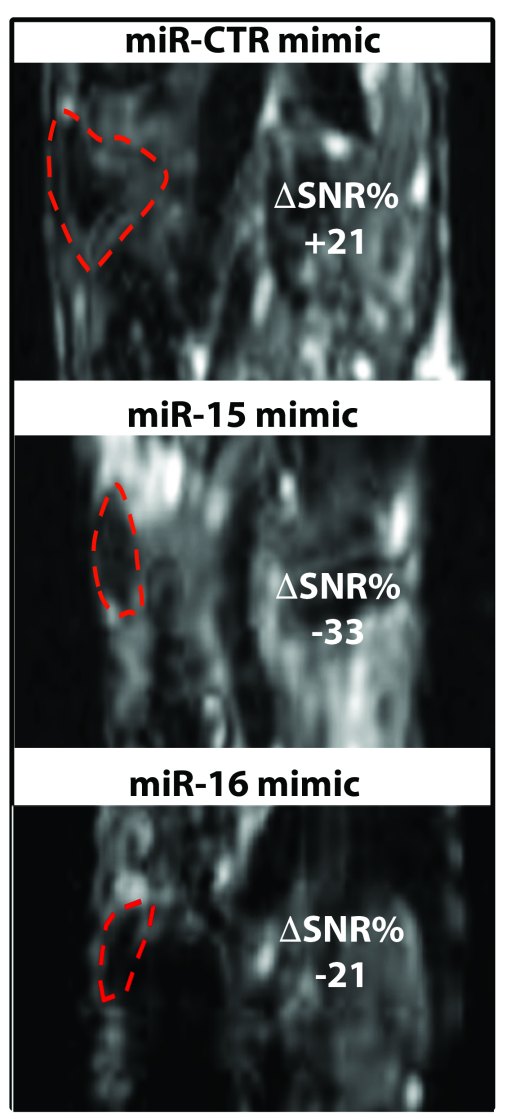

e

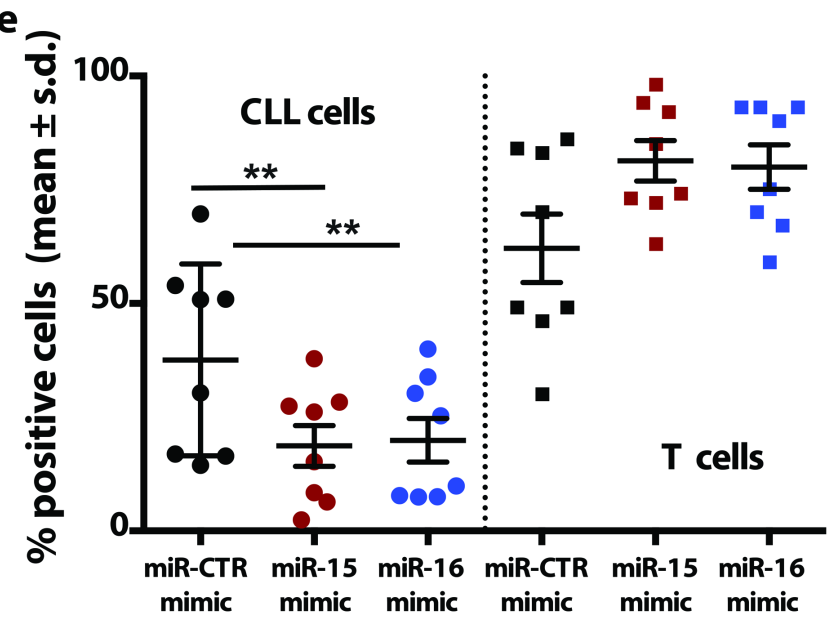

C

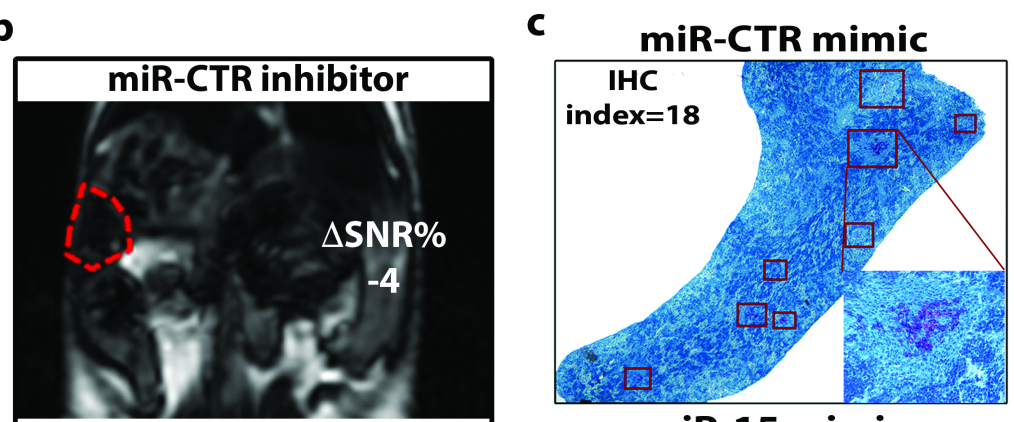

miR-15 mimic

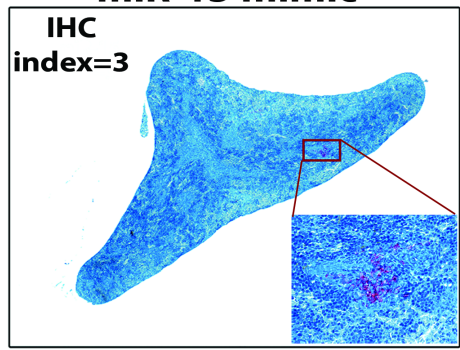

miR-16 mimic
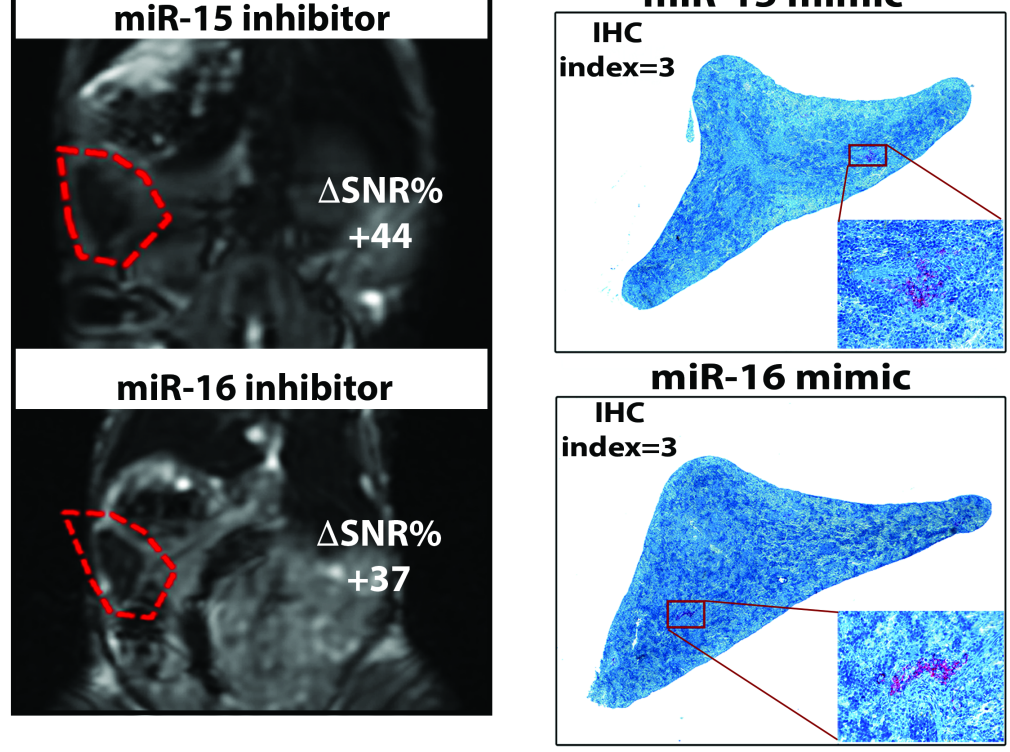

f

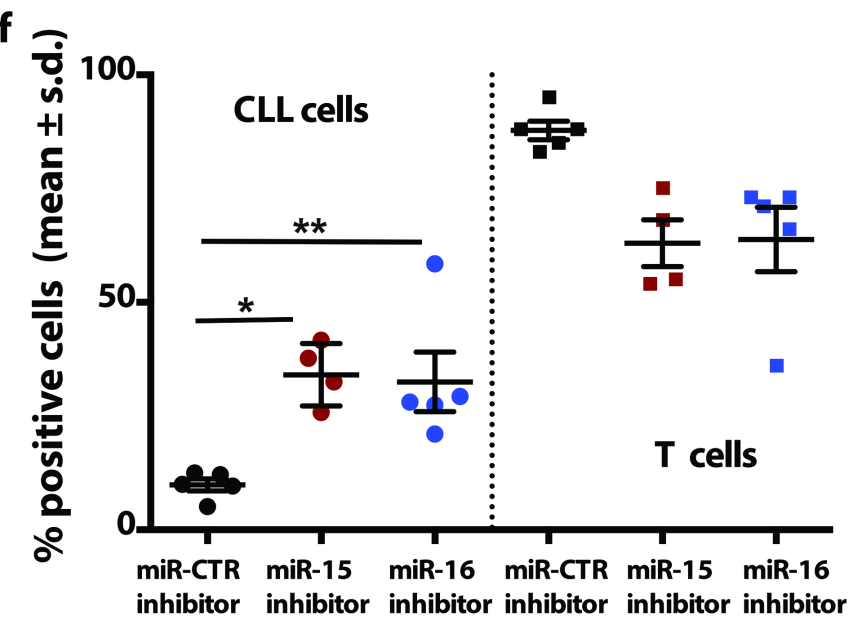

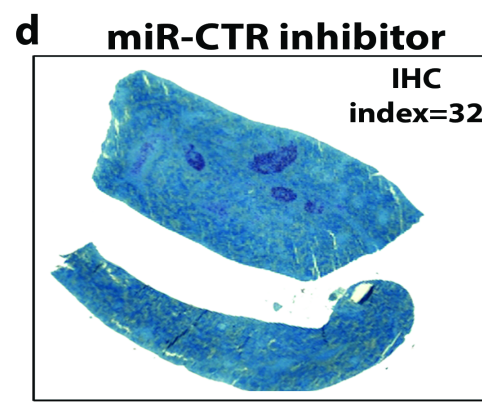

miR-15 inhibitor

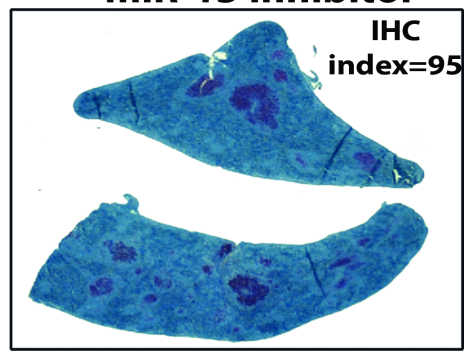

miR-16 inhibitor

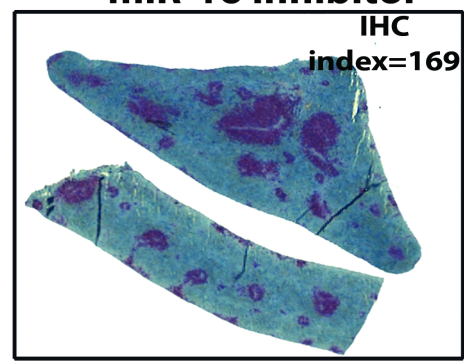

Figure 2 

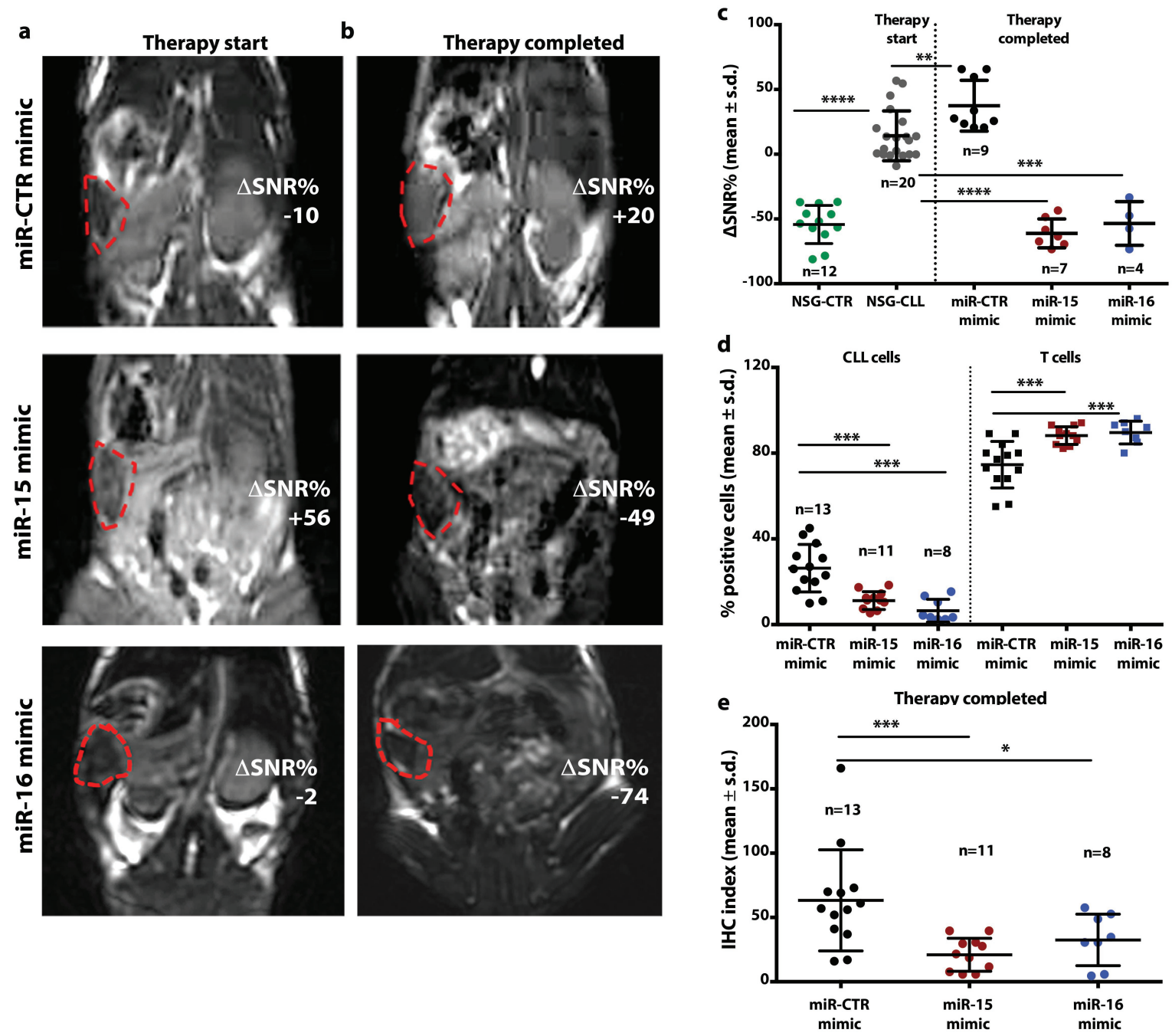

Therapy completed

Figure 3 


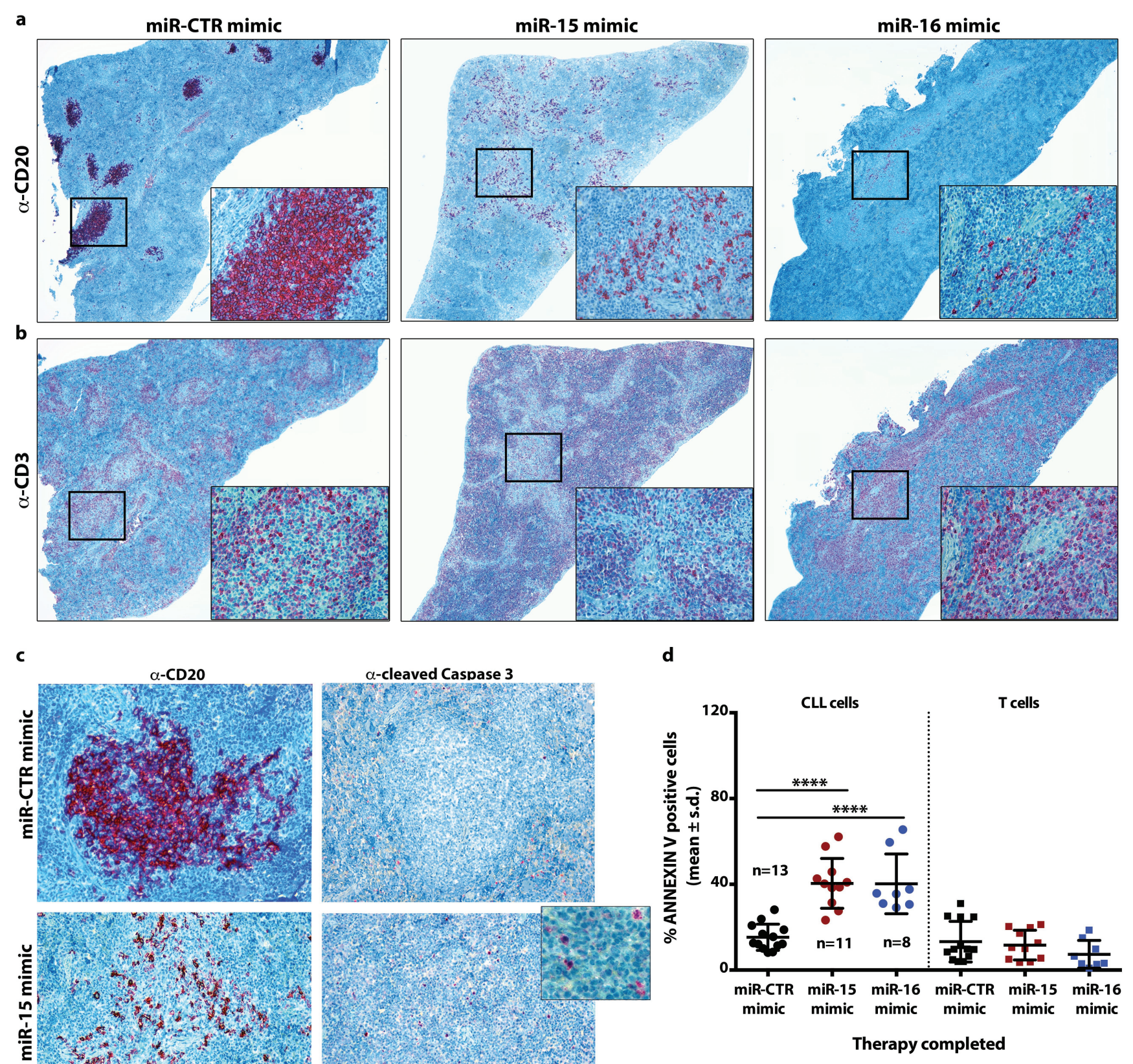

Figure 4 


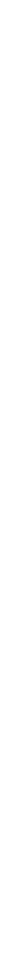

b

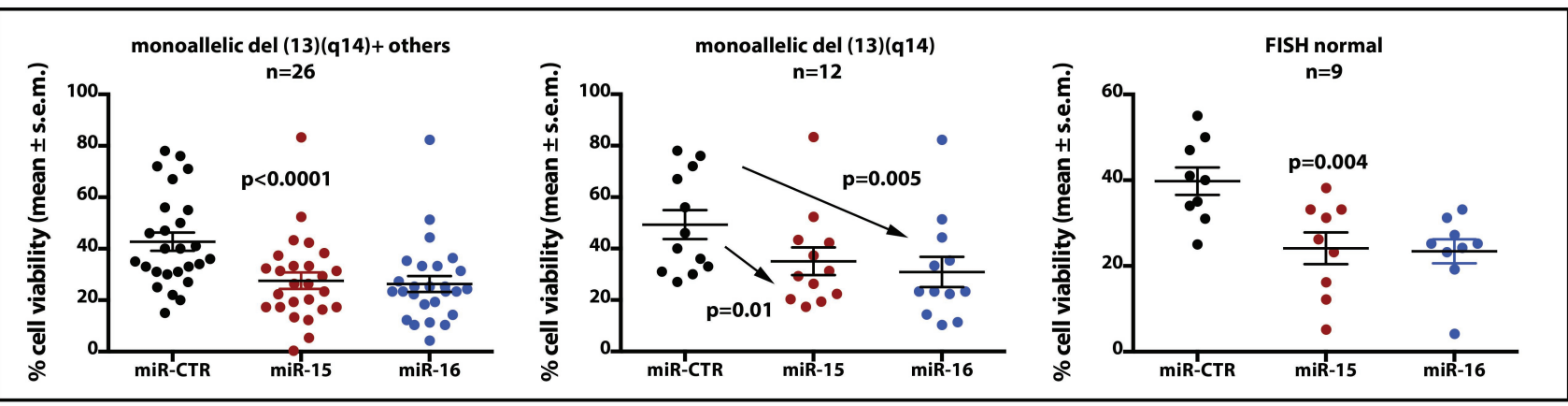

Figure 5 
Table 1. Inhibition of non biallelic del(13q14) CLL cell growth in NSG mice by miR-15 or miR-16 mimic treatment.

\begin{tabular}{|c|c|c|c|c|}
\hline ID & $\begin{array}{c}\text { miRNAs } \\
\text { treatment } \\
\text { (n of mice) }\end{array}$ & $\begin{array}{c}\text { CD45+CD19+CD5+ } \\
\text { CLL cells (FC) } \\
\%(\text { mean } \pm \text { s.d.) }\end{array}$ & $\begin{array}{c}\text { CD45+CD19-CD5+ } \\
\text { T cells (FC) } \\
\% \text { (mean } \pm \text { s.d.) }\end{array}$ & $\begin{array}{c}\text { IHC index } \\
\text { (mean } \pm \text { s.d.) }\end{array}$ \\
\hline \multirow{3}{*}{ FP0499 } & miR-CTR mimic (3) & $9 \pm 1.7$ & $90 \pm 0.9$ & $137 \pm 36.8$ \\
\hline & miR-15 mimic (3) & $4 \pm 0.7$ & $87 \pm 2.1$ & $72 \pm 10.8$ \\
\hline & miR-16 mimic (2) & $2 \pm 0.3$ & $86 \pm 8$ & $26 \pm 7.4$ \\
\hline \multirow{3}{*}{ GN0095 } & miR-CTR mimic (2) & $13 \pm 0.5$ & $82 \pm 2.8$ & $107 \pm 12.7$ \\
\hline & miR-15 mimic (3) & $8 \pm 1.8$ & $86 \pm 2.9$ & $12 \pm 10$ \\
\hline & miR-16 mimic (3) & $7 \pm 0.7$ & $82 \pm 8.5$ & $23 \pm 13.7$ \\
\hline \multirow{3}{*}{ RD0468 } & miR-CTR mimic (4) & $13 \pm 5.4$ & $51 \pm 10.7$ & $56 \pm 5.5$ \\
\hline & miR-15 mimic (3) & $4 \pm 1.4$ & $60 \pm 2.8$ & $12 \pm 5.8$ \\
\hline & miR-16 mimic (3) & $5 \pm 1.5$ & $51 \pm 8.4$ & $14 \pm 9.8$ \\
\hline \multirow{3}{*}{ VS0624 } & miR-CTR mimic (3) & $18 \pm 1.9$ & $81 \pm 2.7$ & $248 \pm 45.1$ \\
\hline & miR-15 mimic (3) & $8 \pm 3.6$ & $87 \pm 7.6$ & $68 \pm 7.5$ \\
\hline & miR-16 mimic (3) & $14 \pm 1.9$ & $79 \pm 6.9$ & $101 \pm 35.1$ \\
\hline \multirow{3}{*}{ RM0626 } & miR-CTR mimic (3) & $46 \pm 12.7$ & $51 \pm 15.4$ & $65 \pm 12.9$ \\
\hline & miR-15 mimic (2) & $58 \pm 2.5$ & $36 \pm 1.4$ & $53 \pm 3.5$ \\
\hline & miR-16 mimic (2) & $63 \pm 1.8$ & $28 \pm 5.4$ & $53 \pm 8.5$ \\
\hline
\end{tabular}

FC= flow-cytometry; IHC index= immunohistochemical index. 